\title{
Heat of Fusion and Crystallization Kinetics of Poly(trifluoroethylene)
}

\author{
Toshiharu YAGI \\ Applications Research Department, Chemical Division, Daikin Kogyo Co., Ltd., \\ 700-1, Hitotsuya, Settsu, Osaka 564, Japan.
}

(Received July 23, 1979)

\begin{abstract}
The crystallization behavior of poly(trifluoroethylene) (PTrFE) has been studied. An electron micrograph of a fractured surface of PTrFE shows the characteristics of lamellar spherulites. The equilibrium melting temperature of PTrFE was found to be $213^{\circ} \mathrm{C}$ from the plot of the crystallization temperature $v s$. the observed melting temperature. The heat of fusion and the entropy of fusion were found to be $1300 \mathrm{cal} \mathrm{mol}^{-1}$ and $2.75 \mathrm{eu} \mathrm{mol}^{-1}$, respectively, from the analysis of polymer-diluent melting data. The surface free energy of the lamella of PTrFE was found to be about $1.2 \mathrm{kcal} \mathrm{mol}^{-1}$ from the melting temperature-lamellar thickness data obtained from the small angle X-ray diffraction method. The crystallization rate of PTrFE was studied by the calorimetric method. The Avrami exponent was found to be about 2.7, and the surface free energy of lamella obtained from the crystallization rate was about $0.79 \mathrm{kcal} \mathrm{mol}^{-1}$. This value seems to give a fairly good agreement with the above results derived by the small angle X-ray diffraction method.

KEY WORDS Poly(trifluoroethylene) / Crystallization / Equilibrium Melting Temperature / Heat of Fusion / Entropy of Fusion / Electron Microscope / Spherulite / Lamellar Crystal / Avrami Exponent /
\end{abstract}

In a previous paper, ${ }^{1}$ we reported the preparation and microstructure of poly(trifluoroethylene) [PTrFE, $\left.-\left(-\mathrm{CF}_{2}-\mathrm{CFH}-\right)_{n}-\right]$, and found that the amount of abnormal head-to-head, tail-to-tail, and tail-to-head linkages in the polymer chain was very large.

We also reported the transition behavior of PTrFE and found that the PTrFE polymer exhibited two transitions ${ }^{2}$ : an upper transition was assigned to the micro-Brownian motion of main chain in amorphous region, and a lower transition to the local molecular motion of main chain in both the crystal and amorphous regions.

In this paper, we are concerned with the crystallization behavior of the PTrFE polymer. The heat of fusion is an extremely important thermodynamic property of semicrystalline polymers. Many papers have presented data on the heat of fusion for fluorinated-ethylene polymers; for example, the heat of fusion is $1920 \mathrm{cal} \mathrm{mol}^{-1}$ for polyethylene ${ }^{3}$ [PE, $\left.-\left(-\mathrm{CH}_{2}-\mathrm{CH}_{2}-\right)_{n}-\right], 1800 \mathrm{cal} \mathrm{mol}^{-1}$ for poly(vinyl fluoride $)^{4}\left[\mathrm{PVF},-\left(-\mathrm{CFH}-\mathrm{CH}_{2}-\right)_{n}-\right], 1435 \mathrm{cal} \mathrm{mol}^{-1}$ or $1400 \mathrm{cal} \mathrm{mol}^{-1}$ for poly(vinylidene fluoride) ${ }^{5.6}$ $\left[\mathrm{PVdF},-\left(-\mathrm{CF}_{2}-\mathrm{CH}_{2}\right)_{n}-\right], 1370 \mathrm{cal} \mathrm{mol}^{-1}$ for poly- (tetrafluoroethylene $)^{7}$ [PTFE, $\left.-\left(-\mathrm{CF}_{2}-\mathrm{CF}_{2}-\right)_{n}-\right]$, and $1200 \mathrm{cal} \mathrm{mol}^{-1}$ for poly(chlorotrifluoroethylene) $)^{8}$ [PCTFE, $\left.-\left(-\mathrm{CF}_{2}-\mathrm{CFCl}-\right)_{n}-\right]$. However, data on $\mathrm{PTrFe}$ are lacking in the literature.

The heat of fusion can be obtained from the depression of the melting temperature $\left(T_{\mathrm{m}}\right)$ by changing the volume fraction of the diluent or by changing the fractions of the second component in the copolymer. ${ }^{9.10}$

The investigation of the kinetic and mechanism of the crystallization is also very important, since the bulk properties of the polymers are largely affected by the transition from the amorphous to crystal state. The dilatometric and calorimetric methods are the main means for studying the crystallization rate of a polymer. ${ }^{11}$ In this study, the calorimetric method was employed, since the nature of crystallization is due to enthalpy change.

The purpose of this study is concerned with the crystallization behavior of PTrFE. This study deals with crystal morphology, the equibrium melting temperature, the heat of fusion, the surface free energy, and the crystallization rate of the PTrFE polymer. 


\section{EXPERIMENTAL}

The preparation and microstructure of PTrFE are described in a previous paper. ${ }^{1}$ The preparation of trifluoroethylene (TrFE)-chlorotrifluoroethylene (CTFE) copolymers will soon be reported on. ${ }^{12}$

The intrinsic viscosity of the PTrFE polymer in dimethylformamide (DMF) was found to be $2.2 \mathrm{dlg}^{-1}$ at $30^{\circ} \mathrm{C}$.

The polymer-diluent mixture was prepared by adding, in a glass tube, the PTrFE polymer to a desired amount of diluent dimethylacetamide (DMAc). After being sealed, the tube was heated to about $270^{\circ} \mathrm{C}$ in slot-bath for at least 5 hours to ensure homogeneous solution, and then brought down to room temperature.

Thermal analysis was performed with a differential scanning calorimeter (Perkin-Elmer DSC-2). An aluminum pan was used to contain the specmen and the weight of each specimen was about $10 \mathrm{mg}$. A heating rate of $10^{\circ} \mathrm{C} / \mathrm{min}$ was used throughout the experiments. The maximum DSC endotherm of fusion was assumed at the melting temperature $T_{\mathrm{m}}$ of the polymer sample. The temperature calibration was based on indium, tin and lead standard.

To study the effects of isothermal crystallization, the samples were maintained at $250^{\circ} \mathrm{C}$ for at least $30 \mathrm{~min}$ to ensure complete melting of the PTrFE crystals. Each sample was then cooled rapidly at a rate of $80^{\circ} \mathrm{C} / \mathrm{min}^{-1}$ to the predetermined crystallization temperature $(453.0,454.0,455.0,456.0,457.0$, 458.0 , and $459.0 \mathrm{~K}$ ) and the exothermic crystallization curve was recorded.

For the study of the morphology of the PTrFE crystal, an electron microscope (Hitachi, model $\mathrm{H}$ 500) was used. The isothermally crystallized bulk sample was measured. PTrFE polymer was maintained at $250^{\circ} \mathrm{C}$ for $30 \mathrm{~min}$ to ensure complete melting of the crystal before cooled at $1.25^{\circ} \mathrm{C} \mathrm{min}^{-1}$ to crystallization temperature, $T_{\mathrm{c}}$. The sample was isothermally crystallized at $185^{\circ} \mathrm{C}$ for 5 hours, and then cooled to room temperature at $1.25^{\circ} \mathrm{C} \mathrm{min}^{-1}$. And then, the sample was fractured at the liquid nitrogen temperature. The fractured surface was prepared by the replication method.

The lamellar thickness of for each sample was estimated by the small angle $\mathrm{X}$-ray diffraction method with a Rigaku-Denki diffractometer. Specimens of the different lamellar thicknesses were prepared by the changing time and temperature of the annealing process.

\section{RESULTS AND DISCUSSION}

\section{Electron Micrograph}

Figure 1 shows an electron micrograph of the fractured PTrFE crystal. The sample was annealed for 5 hours at $185^{\circ} \mathrm{C}$ to allow the crystai to grow enough. These electron micrographs show the distinct characteristics of the lamellar spherulites. The lamellar thickness of this polymer was estimated to be about $600 \AA$, or indicating that the PTrFE crystal is not an extended chain but a folding chain.

\section{Equilibrium Melting Temperature}

Figure 2 shows a plot of the crystallization temperature, $T_{\mathrm{c}}, v s$. the observed melting temperature. $T_{\mathrm{m}}$, for the PTrFE polymer; i.e., a Hoffman-Week plot. ${ }^{13}$ A linear relationship is observed between $T_{\mathrm{c}}$ and $T_{\mathrm{m}}$. The value of the equilibrium melting point,
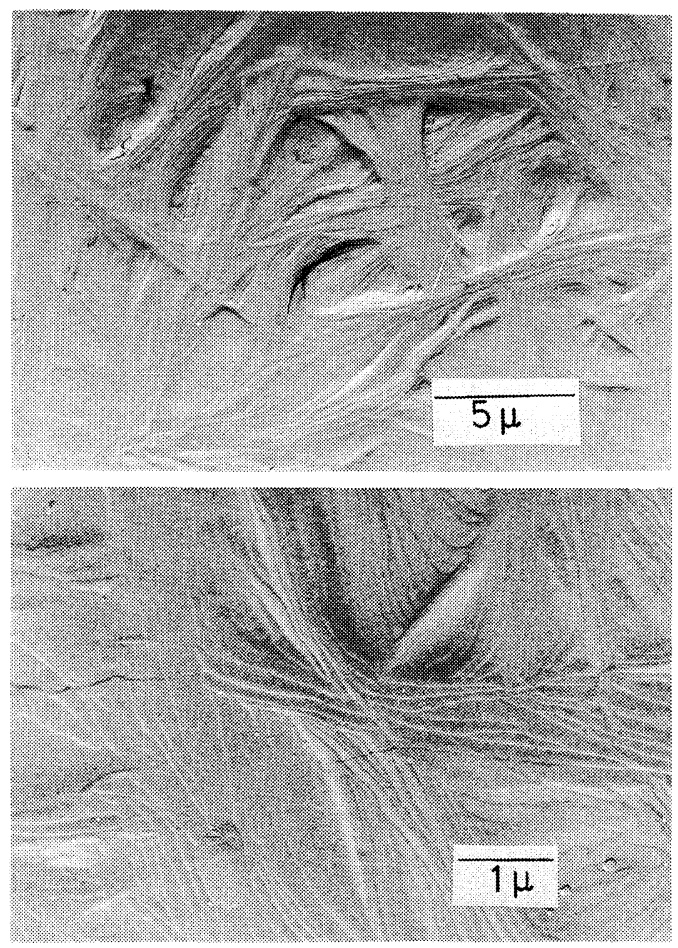

Figure 1. The electron micrographs of replica of the fractured PTrFE polymer. Spherulites (upper diagram) and lamella (lower diagram) can be seen. The sample was annealed for 5 hours at $185^{\circ} \mathrm{C}$. 
Heat of Fusion of Poly(trifluoroethylene)

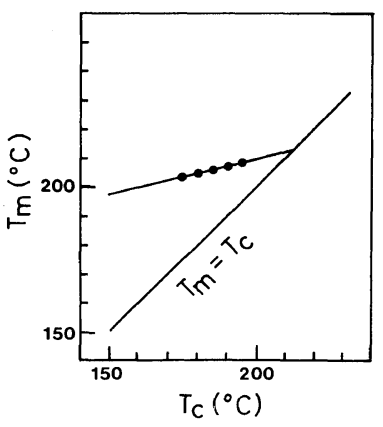

Figure 2. A plot of the crystallization temperature, $T_{\mathrm{c}}$, $v s$. the observed melting temperature, $T_{\mathrm{m}}$, for PTrFE polymer. The $T_{\mathrm{c}} v s . T_{\mathrm{m}}$ line intersects the line $T_{\mathrm{c}}=T_{\mathrm{m}}$ at $213^{\circ} \mathrm{C}$.

$T_{\mathrm{m}}{ }^{\circ}$, can be obtained by a linear extrapolation of the apparent melting temperature. The $T_{\mathrm{c}}$ vs. $T_{\mathrm{m}}$ line intersects with the $T_{\mathrm{m}}=T_{\mathrm{c}}$ line at $213^{\circ} \mathrm{C}$.

Assuming that the crystal is perfect and that the heating process used in the melting temperature determination does not disturb the nature of the crystal, the depression in the melting temperature of the crystal resulting from its finite size is represented by, ${ }^{10.13}$

$$
T_{\mathrm{m}}{ }^{\circ}-T_{\mathrm{m}}=\phi\left(T_{\mathrm{m}}{ }^{\circ}-T_{\mathrm{c}}\right)
$$

where $\phi$ is the stability parameter which depends on the crystal thickness. Equation 1 indicates that $T_{\mathrm{m}}$ should be a linear function of $T_{\mathrm{c}}$, and that $\phi$ is constrained to lie between 0 and 1 . The condition, $\phi=0$ represents the maximum stability and $\phi=1$ represents the inherent unstability. The $\phi$ value of PTrFE is found to be about 0.26 using eq 1 . This value suggests that the PTrFE crystal should be fairly stable. Nishi and Wang ${ }^{14}$ reported a comparable value of PVDF as $\phi=0.2$. Comparing the data for PTrFE and PVDF, there is probably not much difference, as with other polymers as well. ${ }^{13}$

Figure 3 shows the change in the melting temperature $T_{\mathrm{m}}$ with diluent. The data for DMAc as the diluent are well represented by a straight line. Extrapolation of this line to zero diluent concentration yields $T_{\mathrm{m}}=199^{\circ} \mathrm{C}$. This value is roughly $14^{\circ}$ less than the equilibrium melting temperature $T_{\mathrm{m}}^{\circ}$.

\section{Heat of Fusion}

The heat of fusion, $\Delta H_{\mathrm{u}}$, can be obtained from the depression of the melting temperature by varying the

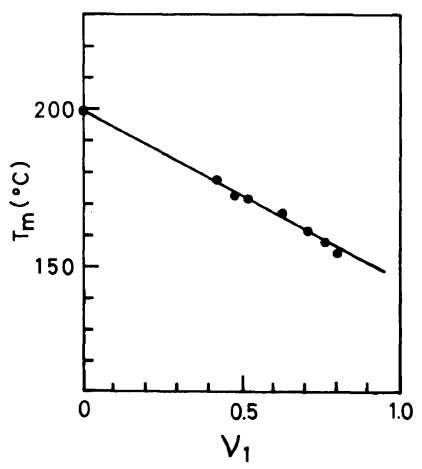

Figure 3. Dependence of the melting temperature, $T_{\mathrm{m}}$, of PTrFE polymer with the volume fraction, $v_{1}$, of dimethylacetamide (DMAc).

volume fraction of the diluent, ${ }^{9,10}$

$$
\begin{aligned}
1 / T_{\mathrm{m}}- & 1 / T_{\mathrm{m}}{ }^{\circ}=\left(R / \Delta H_{\mathrm{u}}\right)\left(v_{\mathrm{u}} / v_{1}\right) \\
\times & {\left[v_{1}-\left(B V_{1} / R T_{\mathrm{m}}\right) v_{1}^{2}\right] }
\end{aligned}
$$

where $T_{\mathrm{m}}{ }^{\circ}$ is the melting temperature of undiluent polymer, $T_{m}$, the melting temperature of polymer-diluent system, $R$, the gaseous constant, $\Delta H_{\mathrm{u}}$, the heat of fusion, $V_{\mathrm{u}}$, the molar volume of polymer repeating unit, $V_{1}$, the molar volume of the diluent, $v_{1}$, the volume fraction of diluent, and $B$, the interaction parameter.

Figure 4 shows a plot of the quantity

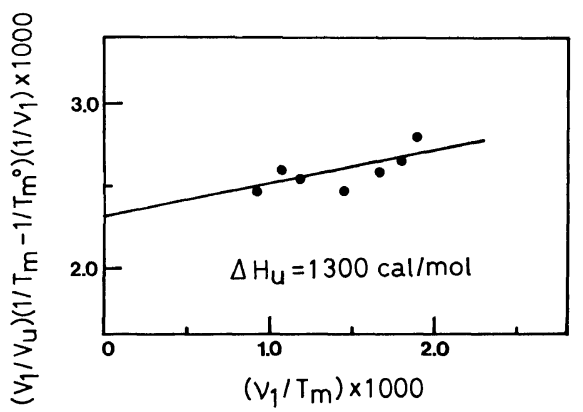

Figure 4. A plot of the quantity $\left(v_{1} / v_{\mathrm{u}}\right)\left(1 / T_{\mathrm{m}} 31 / T_{\mathrm{m}}{ }^{\circ}\right) / v_{1}$ vs. $v_{1} / T_{\mathrm{m}}$ for the PTr-FE-dimethylacetamide system.

$\left(v_{1} / v_{\mathrm{u}}\right)\left(1 / T_{\mathrm{m}}-1 / T_{\mathrm{m}}{ }^{\circ}\right) / v_{1}$ vs. $v_{1} / T_{\mathrm{m}}$ for the PTrFEDMA system. From the straight line, the $\Delta H_{\mathrm{u}}$ of $\mathrm{PTrFE}$ was found to be about $1300 \mathrm{cal} \mathrm{mol}^{-1}$. Since the equilibrium melting temperature, $T_{\mathrm{m}}{ }^{\circ}$, is $213^{\circ} \mathrm{C}$, the equilibrium melting entropy, $\Delta S_{\mathrm{u}}$, was calculated as $2.75 \mathrm{eu} \mathrm{mol}^{-1}$.

The heat of fusion can be also obtained from the 
polymer composition-melting temperature relationship in the copolymer, ${ }^{9,10}$

$$
1 / T_{\mathrm{m}}-1 / T_{\mathrm{m}}{ }^{\circ}=-\left(R / \Delta H_{\mathrm{u}}\right) \ln x_{\mathrm{a}}
$$

where $x_{\mathrm{a}}$ is the molar fraction of $a$-component in the copolymer. Figure 5 shows a plot of $1 / T_{\mathrm{m}} v s . \ln x_{\mathrm{a}}$ in the TrFE-CTFE system. (The detailed process of the preparation and microstructure are reported in another paper. $)^{11}$ The $\Delta H_{\mathrm{u}}$ is calculated as 1050 cal $\mathrm{mol}^{-1}$ using eq 1 . This value is a little small compared with that by the diluent method. In general, the heat of fusion obtained by the copolymer method shows smaller values compared with the diluent method. ${ }^{10}$ It was mentioned that the $\Delta H_{\mathrm{u}}$ obtained by the diluent method is more accurate compared with that by the copolymer method, since the value of $\Delta H_{u}$ changes according to the kind of

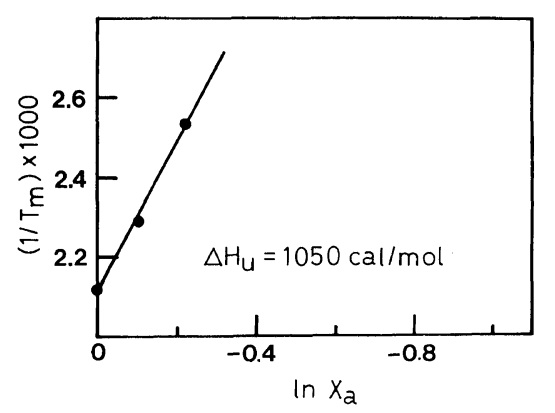

Figure 5. A plot of the $1 / T_{\mathrm{m}}$ vs. $\ln X_{\mathrm{a}}$ for trifluoroethylene (TrFE)-chlorotrifluoroethylene (CTFE) copolymer system. comonomer. ${ }^{10}$ In our study, both the diluent and copolymer methods agree fairly well.

The value of $\Delta H_{\mathrm{u}}$ and $\Delta S_{\mathrm{u}}$ of PTrFE are very similar to those for PCTFE, whose chemical structure differs from PTrFE in that only a hydrogen atom is substituted by a chlorine atom: the values of $\Delta H_{\mathrm{u}}$ and $\Delta S_{\mathrm{u}}$ of PCTFE ${ }^{15.16}$ are $1200 \mathrm{cal} \mathrm{mol}^{-1}$ and $2.49 \mathrm{eu} \mathrm{mol}^{-1}$, respectively.

The values of $T_{\mathrm{m}}, T_{\mathrm{m}}{ }^{\circ}, \Delta H_{\mathrm{u}}$, and $\Delta S_{\mathrm{u}}$ of PTrFE are tabulated in Table I, together with those of other fluorinated ethylene polymers. ${ }^{3,4.6,7,15-17}$ As seen from the table, the values of $\Delta H_{\mathrm{u}}$ and $\Delta S_{\mathrm{u}}$ decrease by increasing the number of fluorine atom in the repeating unit of fluorineted ethylene polymers.

\section{Surface Free Energy of Lamella}

According to the well-known classical theory for the melting temperature of crystals of finite size, the surface free energy of lamella, $\sigma_{\mathrm{e}}$, is given by,

$$
T_{\mathrm{m}}=T_{\mathrm{m}}{ }^{\circ}\left(1-2 \sigma_{\mathrm{e}} / \Delta H_{\mathrm{u}} l\right)
$$

where $l$ is the lamellar thickness, $T_{\mathrm{m}}{ }^{\circ}$, the equibrium melting temperature, and $\Delta H_{\mathrm{u}}$, the heat of fusion. The values of $\Delta H_{\mathrm{u}}$ and $T_{\mathrm{m}}{ }^{\circ}$ are $1300 \mathrm{cal} \mathrm{mol}^{-1}$ and $213^{\circ} \mathrm{C}$, respectively, as mentioned above.

Figure 6 shows a plot of the melting temperature $v s$. the reciprocal lamellar thickness. The lamella thickness was estimated by the small angle X-ray diffraction method. As seen from the figure, the plot of $T_{\mathrm{m}} v s .1 / l$ is linear, and the intercept at $1 / l=0$ gives the equilibrium melting temperature. The value of $1.2 \mathrm{kcal} \mathrm{mol}^{-1}$ for $\sigma_{\mathrm{e}}$ was obtained from the slope of this line.

\begin{tabular}{|c|c|c|c|c|c|}
\hline Polymer & $\frac{T_{\mathrm{m}}}{{ }^{\circ} \mathrm{C}}$ & $\frac{T_{\mathrm{m}}{ }^{\circ}}{{ }^{\circ} \mathrm{C}}$ & $\frac{\Delta H_{\mathrm{u}}}{\mathrm{cal} \mathrm{mol}^{-1}}$ & $\frac{\Delta S_{\mathrm{u}}}{\mathrm{eu} \mathrm{mol}}{ }^{-1}$ & $\frac{\sigma_{\mathrm{e}}}{\mathrm{ergcm}}$ \\
\hline$P E^{a, b}$ & & 143 & 1920 & 4.78 & 57 \\
\hline $\mathrm{PVF}^{\mathrm{c}}$ & 200 & & 1800 & 3.80 & \\
\hline $\mathrm{PVDF}^{\mathrm{d}, \mathrm{e}}$ & 178 & 178 & 1435 & 3.16 & 65 \\
\hline PTrFE & 199 & 213 & 1300 & 2.75 & 54 \\
\hline $\mathrm{PTFE}^{\mathrm{f}}$ & 330 & & 1370 & 2.27 & \\
\hline PCTFE $^{\mathrm{b} g}$ & 218 & 221 & 1200 & 2.49 & 37 \\
\hline
\end{tabular}

Table I. Comparison of the thermodynamic parameters of fluorinated ethylene polymers

a Data of Broadhurst. ${ }^{3}$

b Data of Hoffman. ${ }^{15.16}$

c Data of Sapper. ${ }^{4}$

d Data of Welch. ${ }^{6}$

e Data of Mancarella. ${ }^{17}$

${ }^{f}$ Data of Starkweather. ${ }^{7}$

g Data of Bueche. ${ }^{8}$ 


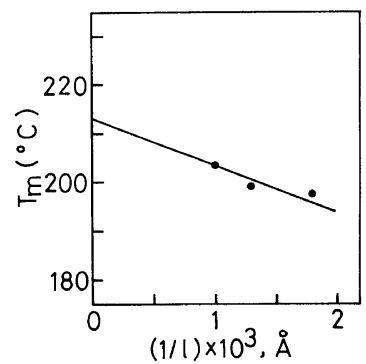

Figure 6. A plot of $T_{\mathrm{m}}$ vs. the reciprocal lamellar thickness $(1 / L)$.

\section{Crystallization Rate}

Figure 7 shows the change in the crystallinity of the PTrFE polymer with isothermal crystallization time, at various crystallization temperatures. From these curves, the half time of conversion, $t_{1 / 2}$, was determined at various crystallization temperature, $T_{\mathrm{c}}$. Figure 8 shows a plot of $t_{1 / 2} v s$. $T_{\mathrm{c}}$. The slope changes at $457 \mathrm{~K}$.

The kinetics of the isothermal crystallization of polymers can be analysed by means of the wellknown Avrami equation, ${ }^{10,19}$

$$
\left(1-X_{t}\right)=\exp \left(-Z t^{n}\right)
$$

The double logarithmic form of eq 5 is given by

$$
\log \left[-\ln \left(1-X_{\mathrm{t}}\right)\right]=n \log (t)+\log (Z)
$$

where $X_{1}$ is the weight fraction of crystallized polymer at time $t, Z$, the rate constant, and $n$, the Avrami exponent. Figure 9 shows the Avrami plots of PTrFE at various crystallization temperatures. As seen from the figure, the crystallization kinetics of PTrFE obeys the Avrami equation. The exponent

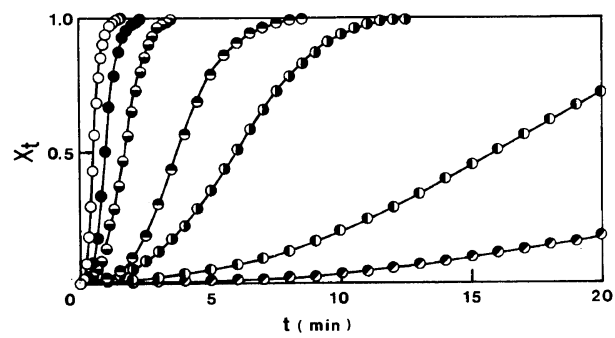

Figure 7. Change in crystallinity, $X_{t}$, of PTrFE polymer with isothermal crystallization time at various crystallization temperatures, $t ; \bigcirc, 453.0 \mathrm{~K} ; \bigcirc, 454.0 \mathrm{~K} ; \ominus$, $455.0 \mathrm{~K} ; \odot, 456.0 \mathrm{~K} ; \bigcirc, 457.0 \mathrm{~K} \odot, 458.0 \mathrm{~K}$; and $\oslash$, $459.0 \mathrm{~K}$.

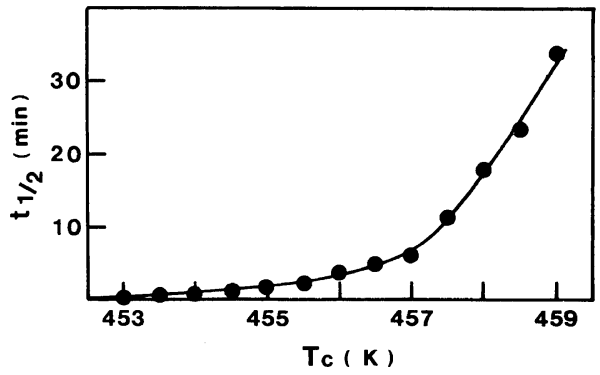

Figure 8. A plot of the crystallization half time, $t_{1 / 2}$, of PTrFE vs. the crystallization temperature, $T_{\mathrm{c}}$.

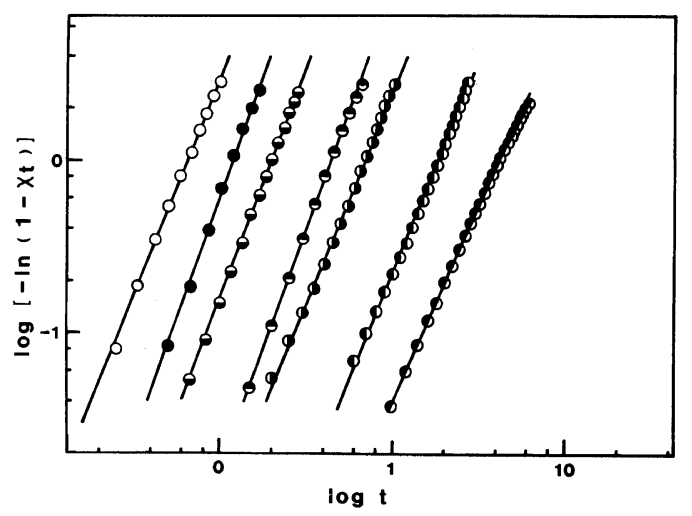

Figure 9. An Avrami plot for the PTrFE polymer at various crystallization temperatures: $\bigcirc, 453.0 \mathrm{~K}$; $454.0 \mathrm{~K} ; \ominus, 455.0 \mathrm{~K} ; \ominus, 456.0 \mathrm{~K} ; \boldsymbol{O}, 457.0 \mathrm{~K} ; \boldsymbol{D}$, $458.0 \mathrm{~K}$; and $\bigcirc, 459.0 \mathrm{~K}$.

changes with the crystallization temperature. The average value of $n$ is found to be about 2.7.

From eq 6 , the kinetic constant $Z$ is given by

$$
Z=\ln \left(2 / t_{1 / 2}^{n}\right)
$$

The crystallization parameters of PTrFE polymer crystallized at each temperature are tabulated in Table I.

\section{Analysis of Crystallization Rate}

According to the theoretical treatment of coherent surface nucleation in a chain fold polymer, given by Hoffman and Lauritzen ${ }^{16,20}$, the free energy of formation of a nucleus of critical dimensions, $\Delta \Phi^{*}$, may be expressed to a good approximation by,

$$
\Delta \Phi^{*}=4 b \sigma \sigma_{\mathrm{e}} / \Delta f_{v}
$$

where $\sigma$ and $\sigma_{\mathrm{e}}$ are the surface free energies per unit 
Table II. Crystallization parameters for PTrFE

\begin{tabular}{|c|c|c|c|}
\hline$T_{\mathrm{c}}^{\mathrm{a}}$ & \multirow{2}{*}{$n^{\mathrm{b}}$} & \multirow{2}{*}{$\frac{t_{1 / 2}^{\mathrm{c}}}{\min }$} & \multirow{2}{*}{$\frac{Z^{\mathrm{d}}}{\min ^{-n}}$} \\
\hline $\mathrm{K}$ & & & \\
\hline 453.0 & 2.5 & 0.56 & 2.95 \\
\hline 453.5 & 2.8 & 0.70 & 1.88 \\
\hline 454.0 & 3.1 & 1.03 & 0.63 \\
\hline 454.5 & 3.1 & 1.41 & 0.245 \\
\hline 455.0 & 2.7 & 1.70 & 0.165 \\
\hline 455.5 & 2.6 & 2.40 & 0.0712 \\
\hline 456.0 & 2.8 & 3.80 & 0.0165 \\
\hline 456.5 & 2.6 & 5.0 & 0.0106 \\
\hline 457.0 & 2.5 & 6.0 & $7.86 \times 10^{-3}$ \\
\hline 457.5 & 2.7 & 11.5 & $9.48 \times 10^{-4}$ \\
\hline 458.0 & 2.8 & 16.0 & $2.95 \times 10^{-4}$ \\
\hline 458.5 & 2.5 & 23.5 & $2.59 \times 10^{-4}$ \\
\hline 459.0 & 2.5 & 34.0 & $1.03 \times 10^{-4}$ \\
\hline
\end{tabular}

a $T_{\mathrm{c}}$, crystallization temperature.

b $n$, the Avrami exponent.

c $t_{1 / 2}$, the half time of conversion.

d $Z$, kinetic rate constant.

area of the surface pararell and perpendicular, respectively, to the molecular chain direction, and $\Delta f_{v}$, the Gibb's free energy difference between the liquid and the crystal. The $\Delta f_{v}$ is given by, ${ }^{16}$

$$
\Delta f_{\mathrm{v}}=H_{\mathrm{u}}\left(\Delta T / T_{\mathrm{m}}{ }^{\circ}\right)
$$

where $\Delta H_{\mathrm{u}}$ is the heat of fusion, $T_{\mathrm{m}}{ }^{\circ}$ the equibrium melting temperature, and $\Delta T=T_{\mathrm{m}}{ }^{\circ}-T_{\mathrm{m}}$, the degree of the supercooling.

According to the kientic theory, ${ }^{20,21}$ the rate of overall crystallization may be expressed by,

$$
\frac{1}{n} \log Z+\frac{\Delta F^{*}}{2.3 k T_{\mathrm{c}}}=A_{\mathrm{n}}-\frac{\Delta \Phi^{*}}{2.3 k T_{\mathrm{c}}}
$$

where $k$ is the Boltzmann constant, $Z$, the rate constant in the Avrami equation, and $\Delta F^{*}$ the activation energy for the transport process at interface. By the conbination of eq 8,9 , and 10 ,

$$
\frac{1}{n} \log Z+\frac{\Delta F^{*}}{2.3 k T_{\mathrm{c}}}=A_{\mathrm{n}}-\frac{4 b_{0} \sigma \sigma_{\mathrm{e}} T_{\mathrm{m}}^{\circ}}{2.3 k \Delta H_{\mathrm{u}} T_{\mathrm{c}} \Delta T}
$$

$\Delta F^{*}$ can be obtained by the WLF equation, ${ }^{22}$

$$
\Delta F^{*}=F_{\mathrm{WLF}}=\frac{C_{1} T_{\mathrm{c}}}{C_{2}+T_{\mathrm{c}}-T_{\mathrm{g}}}
$$

where $C_{1}$ and $C_{2}$ are constants.

Figure 10 shows a plot of $(1 / n) \log Z v s$. $\left(T_{\mathrm{m}}{ }^{\circ} / T_{\mathrm{c}} \Delta T\right)$ for PTrFE. The values for $\sigma$ and $\sigma_{\mathrm{e}}$ were calculated as 7.3 and $54 \mathrm{erg} / \mathrm{cm}^{2}$ respectively, $(0.24$ and $0.79 \mathrm{kcal} \mathrm{mol}^{-1}$, respectively using eq 11). The

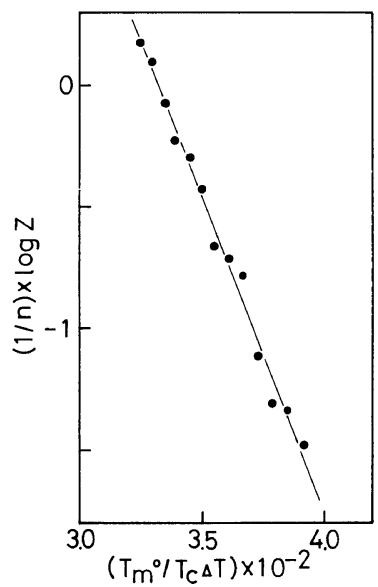

Figure 10. A plot of $(1 / n) \log Z v s .\left(T_{\mathrm{m}}{ }^{\circ} / T_{\mathrm{c}} \Delta T\right)$ for the PTrFE polymer.

value of $\sigma_{\mathrm{e}}$ obtained by the calorimetric method is considerably in good agreement with that of the small angle X-ray diffraction method $\left(\sigma_{\mathrm{e}}=1.2\right.$ $\mathrm{kcal} \mathrm{mol}^{-1}$ ) mentioned above. The value of $\sigma_{\mathrm{e}}$ is also tabulated in Table I, together with those of other fluorinated ethylene polymers. It is of intersting to note that crystals of other fluorinated ethylene polymers also yield comparable values for $\sigma_{\mathrm{e}}$.

Acknowledgements. The author wishes to thank professor A. Nakajima of Kyoto University for his valuable comments and suggestions, and Dr. Y. Kubouchi, Dr. Y. Kometani, and Mr. M. Tatemoto of Daikin Kogyo Co., Ltd., for their stimulating discussions and encouragement.

\section{REFERENCES}

1. T. Yagi, Polym. J., 11, 353 (1979).

2. T. Yagi, Polym. J., 11, 711 (1979).

3. M. G. Broadhurst, J. Res. Natl. Bur. Stand., 67A, 233 (1963).

4. D. I. Sapper, J. Polym. Sci., 43, 383 (1960).

5. K. Nakagawa and Y. Ishida, J. Polym. Sci., Phys. Ed., 11, 2153 (1973).

6. G. J. Welch, J. Polym. Sci., Polym. Phys. Ed., 14, 1683 (1976).

7. H. W. Starkweather, Jr. and R. H. Boyd, J. Phys. Chem., 64, 410 (1960).

8. A. M. Bueche, J. Am. Chem. Soc., 74, 65 (1952).

9. P. J. Flory, "Priciples of Polymer Chemistry," Cornell University Press, Ithaca, N.Y., 1953.

10. L. Mandelkern, "Crystallization of Polymers," 
Heat of Fusion of Poly(trifluoroethylene)

McGraw-Hill, New York, N.Y., 1964.

11. Yu. K. Godovsky and G. L. Slonismky, J. Polym. Sci., Polym. Phys. Ed., 12, 1053 (1974).

12. T. Yagi and M. Tatemoto, submitted to Polym. J.

13. J. D. Hoffman and J. J. Weeks, J. Res. Natl. Bur. Stand., 66A, 13 (1962).

14. T. Nishi and T. T. Wang, Macromolecules, 8, 909 (1975).

15. J. D. Hoffman and J. J. Week, J. Chem. Phys., 37, 1723 (1962).

16. J. D. Hoffman, SPE Trans., 4, 315 (1964).
17. C. Mancarella and E. Martuscelli, Polymer, 18, 1240 (1977).

18. P. J. Flory, J. Chem. Phys., 17, 223 (1949).

19. B. Wunderlich, "Macromolecular Physics," Vol. 2, Academic Press, New York, N.Y., 1976.

20. J. I. Lauritzen and J. D. Hoffman, J. Chem. Phys., 31, 1680 (1959).

21. D. Turnbull and J. C. Fisher, J. Chem. Phys., 17, 71 (1949).

22. M. L. Williams, R. F. Landel and J. D. Ferry, J. Am. Chem. Soc., 77, 3701 (1955). 